\title{
Trabalho Escravo, Direitos Humanos e Exclusão Social
}

\author{
Eduardo Cambi \\ Pós-doutor pela Università degli Studi di Pavia, UNIPV, \\ Itália. Doutor em Direito pela Universidade Federal do \\ Paraná (UFPR). Professor efetivo dos cursos de Pós- \\ -Graduação Stricto Sensu - Mestrado e Doutorado - e \\ do curso de Graduação da Faculdade de Direito do Centro \\ de Ciências Sociais Aplicadas da Universidade Estadual do \\ Norte do Paraná (Uenp) - Campus de Jacarezinho. Pro- \\ fessor da Universidade Paranaense - Unipar. Promotor de \\ Justiça do Estado do Paraná. Coordenador do Centro de \\ Estudos e Aperfeiçoamento Funcional (Ceaf) do Ministério \\ Público do Paraná. Membro colaborador da Comissão de \\ Direitos Fundamentais do Conselho Nacional do Ministé- \\ rio Público (CNMP). eduardocambi@hotmail.com
}

\section{Danieli A. C. Leite Faquim}

Mestranda em Ciência Jurídica pela Universidade Estadual do Norte do Paraná (Uenp). Mestranda em Ensino pelo PPGEN Uenp Campus Cornélio Procópio. Especialista em Direito do Trabalho. Especialista em Educação Ambiental. Professora Universitária. Advogada. danieli_leite@hotmail.com

\section{Resumo}

0 presente artigo faz uma análise do trabalho escravo contemporâneo a partir dos direitos humanos e da exclusão social promovida pela escravidão. As reflexões da prática da escravidão de trabalhadores no passado correlacionam-se à existência de uma prática contemporânea de trabalho escravo resultante dos desígnios da acumulação de capital. 0 tema objetiva demonstrar as condições degradantes e humilhantes de trabalho dos escravos, assim como a supressão dos seus direitos fundamentais básicos, como a liberdade e a dignidade, e os direitos humanos feridos por essa realidade deplorável. Considerando a busca da real liberdade do trabalhador e a garantia de seus direitos fundamentais, afirma-se a importância da repressão do trabalho em condições análogas às de escravo e se esclarece sobre a necessidade da promoção de ações preventivas e inclusivas das vítimas e das pessoas em 
situação de vulnerabilidade. Utilizou-se o método dedutivo, uma vez que o trabalho é iniciado com argumentos gerais voltados para considerações sobre a exclusão social promovida pela escravidão contemporânea.

Palavras-chave: Dignidade. Direitos humanos. Exclusão social. Trabalho escravo.

\title{
Slave Labor, Human Rights and Social Exclusion
}

\begin{abstract}
This article analyzes contemporary slave labor based on neglected human rights and social exclusion promoted by slavery. The reflections of the practice of the slavery of workers in the past correlates to the existence of a contemporary practice of slave labor resulting from the designs of capital accumulation. The theme aims at demonstrating the degrading and humiliating conditions of the slaves' work, as well as the suppression of their basic fundamental rights, such as freedom and dignity, and the human rights that are harmed by this deplorable reality. Considering the search for the real freedom of the worker and the guarantee of their fundamental rights, it affirms the importance of the repression of the work in conditions analogous to those of slave and it clarifies on the necessity of the promotion of preventive and inclusive actions of the victims and the people in situation of vulnerability.
\end{abstract}

Keywords: Dignity. Human rights. Social exclusion. Slave work.

Recebido em: 26/6/2017

Revisões requeridas em: 21/11/2017

Aprovado em: 12/12/2017

\section{Sumário}

1 Introdução. 2 Aspectos históricos relevantes da escravidão brasileira. 3 Trabalho escravo contemporâneo. 4 A construção dos direitos humanos com foco na inclusão social. 50 clamor pela efetividade dos direitos humanos no tocante à marginalização social. 60 trabalho em condições análogas às de escravo como grave violação dos direitos humanos. 7 Considerações finais. 8 Referências. 


\section{INTRODUÇÃO}

O presente artigo traz à baila o tema trabalho escravo contemporâneo: mazela que fere os direitos humanos e promove a exclusão social, a fim de afirmar a realidade atual em relação à escravidão a partir das novas perspectivas do direito moderno, que contempla a primazia dos diretos fundamentais de liberdade e dignidade humana.

A escolha do tema se dá pelo fato de considerar que, embora a escravidão seja um meio antigo de supressão de direitos, sua essência se perpetuou e ainda é corriqueira na atualidade, inclusive com requintes de crueldades morais. Constata-se que a escravidão contemporânea é uma forma de exclusão social, uma vez que os escravos contemporâneos são agredidos moral e juridicamente, o que afeta a sua sobrevivência digna.

Apesar de o trabalho escravo parecer ser um acontecimento do passado, calcula-se que milhões de pessoas, incluindo mulheres e crianças, continuam sendo traficadas para diversas partes do mundo para alimentar a famigerada forma de exploração do homem pelo homem, denominada pelo economista escocês Adam Smith, no século, 18 de “aberração”. Infelizmente, no entanto, o Brasil é um dos países que mais contribuem com essa monstruosidade.

A discussão acerca do tema da escravidão contemporânea é de suma importância, posto que tal condição laboral atinge intensamente a sociedade. Logo, impacta a economia do país, e fere os direitos fundamentais do ser humano e a legislação trabalhista. Por esse motivo, a prática do trabalho escravo é um dos assuntos em evidência na mídia e um dos graves problemas que o governo federal tem procurado solucionar por meio de políticas voltadas a sua erradicação. 
Sob o aspecto econômico, é certo que do trabalho pode-se objetivar o lucro, mas jamais poderá ser desconsiderado o bem-estar do trabalhador, o que, evidentemente, não ocorre nos cenários de trabalho em condições análogas às de escravo.

Com efeito, o presente artigo fará uma breve abordagem histórica do trabalho escravo no Brasil, além de tratá-lo como uma mazela, evidenciando a condição degradante e humilhante desses trabalhadores.

Ao final, o texto pretende ressaltar que o trabalho escravo é uma forma cruel de exploração humana, que deve ser banido da sociedade para que o trabalho possa ser exercido em condições dignas.

\section{ASPECTOS HISTÓRICOS RELEVANTES DA ESCRAVIDÃO BRASILEIRA}

A realidade escravista, em pleno século 21, e seus reflexos sociais, econômicos, financeiros, ambientais e psicológicos, bem como as violações de direitos na contemporaneidade, devem ser compreendidos a partir do viés histórico, uma vez que no período colonial o Brasil vivenciou intenso tráfico de escravos com a África, como apresenta Costa e Silva (2012, p. 25):

Carregados de aguardente, farinha de mandioca, tabaco em rolo e carne-seca, além de artigos importados via Portugal, como tecidos, objetos de latão e cobre, cutelaria e armas de fogo, os navios partiam diretamente do Rio de Janeiro para Luanda ou Benguela e de Salvador para Ajudá ou Lagos, e regressavam também diretamente com escravos. Até mesmo os vultosos capitais que alimentavam esse comércio - o maior negócio do Brasil e que influenciava todos os outros - eram predominantemente originários da colônia e não da metrópole.

Neste ínterim, o historiador social e sociólogo britânico, Robin Blackburn, afirma que: 
No Brasil, durante o governo de Mem de Sá (1557-1572), desenvolve-se a economia açucareira, com "mão-de-obra mista de escravos africanos e índios". Destaque-se que o "açúcar trouxe prosperidade ao Brasil nas últimas décadas do século, e por mais de cem anos os africanos foram trazidos para a colônia para trabalhar nas propriedades açucareiras" (2003, p. 206).

Apesar da independência, das transformações urbanísticas, mudanças de gosto, valores e comportamento e toda a influência da Europa, “o que não se alterou foi a divisão da população em homens livres e escravos. O regime escravista continuou intacto, se é que não se fortaleceu" (COSTA E SILVA, 2012, p. 30).

Ainda, conforme as palavras do historiador Alberto da Costa e Silva, o Brasil era uma sociedade escravista;

Mesmo nas cidades maiores, velhos hábitos resistiram à pressão das novidades. O mais desapontador de tudo: não se tocou no sistema escravista. E, pelas ruas do Rio de Janeiro, do Recife ou de Salvador, continuaram a passar negros com grilhões ao pescoço e máscaras de flandres. E a ser açoitados no pelourinho. Muito mudara para alguns, e nada ou pouco para a maioria. (...) O país assentava-se na agricultura e na pecuária e, embora continuasse a crescer a produção para o mercado interno, o que mais chamava a atenção era a grande propriedade rural movida pelo trabalho escravo e votada à exportação (2012, p. 33).

A partir do fim do Primeiro Reinado aumentaram os preços dos escravos, motivo pelo qual muitos senhores começaram a se preocupar mais com eles, inclusive vários já não dormiam nas senzalas, como era o caso daqueles que prestavam serviços domésticos, pois tinham acomodações próprias na casa-grande, nos fundos do prédio, nas águas-furtadas ou no porão. 
Observa-se, contudo, que o prestígio e riqueza dos senhores mediam-se principalmente pelo número de seus escravos. Como descreve Costa e Silva,

Os que possuíam muitos cativos faziam questão de, ao ir à missa de domingo, por exemplo, serem acompanhados por alguns deles, as escravas cheias de jóias e vestidas de seda ou algodões finos, com rendas e bordados, e os homens de coletes, camisas com folhos e calças cingidas às pernas. Uns e outros, porém, quase sempre descalços, porque era da condição do escravo andar de pé no chão (2012, p. 44).

A extinção do uso da mão de obra escrava no Brasil se deu por um processo lento e gradual, com vistas à transição para a formação de um mercado de trabalho livre. Foram três sucessivas leis de locação de serviços de 1830, 1837 e 1879, em que o Estado brasileiro proporcionou uma intervenção específica acerca do tema:

(...) a segunda metade do século XIX é um período marcado pela preocupação de constituição e regulamentação legal do uso do trabalho livre no Brasil. A regulação dessas novas modalidades de uso da mão-de-obra contou com a mediação do Estado (Império) disciplinando os contornos do trabalho livre. Conquanto haja uma inexplicável lacuna na bibliografia do direito do trabalho, as leis de locação de serviços de 1830, 1837 e 1879, representam o principal marco de intervenção estatal na contratação do trabalho livre no Brasil (MACHADO, 2012, p. 155).

Foi somente a Lei Áurea, assinada em 13 de maio de 1888, que decretou o fim do direito de propriedade de uma pessoa sobre outra, após as pressões realizadas pela Inglaterra para pôr fim à escravidão:

Com a consolidação do sistema capitalista, ao longo do século XIX, os ideais escravagistas brasileiros mostraram-se incompatíveis com a realidade mundial emergente. Isso porque o trabalho livre era elemento indispensável à consolidação e expansão dos mercados dos países de orientação capitalista. (...) Sendo assim, tendo em vista o novo cenário 
mundial e a pressão exercida pelos países capitalistas -especialmente a Inglaterra -, a princesa Isabel aboliu, em 1988, o regime escravocrata brasileiro, com a promulgação da Lei Áurea (MIRAGLIA, 2011, p. 133).

O Código Penal, no artigo 149 , com redação dada pela Lei $\mathrm{n}^{\mathrm{o}}$ 10.803/2003, considera crime a seguinte conduta:

Reduzir alguém à condição análoga à de escravo, quer submetendo-o a trabalhos forçados ou à jornada exaustiva, quer sujeitando-o a condições degradantes de trabalho, quer restringindo, por qualquer meio, sua locomoção em razão de dívida contraída com o empregador ou preposto, a vigilância ostensiva no local de trabalho, a posse de documentos ou objetos pessoais do trabalhador, por parte do empregador ou seu preposto, com o fim de retê-lo no local de trabalho.

Infelizmente, no Brasil, apesar da abolição da escravatura, o trabalho escravo nunca deixou de existir, tendo apenas mudado a sua roupagem.

É importante destacar que o trabalho em condições análogas às de escravo contraria o Estado Democrático de Direito, a quem incumbe assegurar o exercício dos direitos fundamentais e tem o dever de perseguir a inclusão social do trabalhador, conjuntamente com a busca pelo equilíbrio entre as classes detentoras do capital e do trabalho.

Para tanto, é essencial conceber o trabalho com noção diversa de sofrimento, dor e tortura, por se tratar de um direito fundamental social (artigo $6^{\circ} / \mathrm{CF}$ ), sendo indispensável a preocupação com a efetivação desse direito e a inclusão do trabalhador brasileiro no mercado de trabalho.

\section{TRABALHO ESCRAVO CONTEMPORÂNEO}

Apesar da Lei Áurea ter abolido a escravidão, o trabalho escravo e degradante se manteve de outras formas, pois, em pleno século 21, no Brasil, ainda há trabalhadores em condições análogas às de escravo e 
empregadores com mentalidade e comportamentos escravocratas, que reduzem seus subordinados à condição de objetos, mantendo a chaga social escravista.

A escravidão contemporânea é caracterizada por trabalhadores oprimidos, vítimas de humilhações constantes, situação acentuada pelas desigualdades sociais, econômicas, raciais e culturais, que culminam no fenômeno da coisificação da pessoa humana.

$\mathrm{Na}$ atualidade, o trabalho escravo no Brasil configura "uma realidade em que não se trata mais de cor de pele ou raça, mas incide no aproveitamento da miséria e desespero daqueles que não veem possibilidade de inserir-se no meio social” (TREVISAM, 2015, p. 20).

É importante ressaltar que a escravidão contemporânea está presente tanto no âmbito urbano, como nas confecções de costura, quanto no meio rural. No âmbito urbano, no entanto, é temerário precisar dados, pois muitas das atividades que mantêm mão de obra escrava são clandestinas. Já no meio rural a fiscalização e as pesquisas são capazes de fornecer informações pontuais, conforme segue.

De acordo com pesquisa feita pela Organização Internacional do Trabalho no Brasil, os trabalhadores em condição análoga à de escravo no meio rural, em sua maioria, são constituídos de não brancos, ou seja, negros, pardos e indígenas, sendo que os negros e pardos equivalem a $80 \%$ dos trabalhadores nessa situação, enfatizando-se que a proporção de negros, entre os trabalhadores nessas condições é de 2,5 vezes superior ao índice encontrado na população brasileira, que é de $6,9 \%$ (ORGANIZAÇÃO..., 2011, p. 57).

O trabalho na condição análoga a de escravos é resultante da ausência de políticas públicas de integração dos ex-escravos ao meio social, da grande oferta de mão de obra e da escassez de postos de trabalho, que fazem com que os trabalhadores se submetam a condições indignas. 
Cabe salientar que, embora tenha libertado os negros das senzalas, $o$ governo brasileiro não se preocupou em criar normas e/ou condições para que o antigo escravo se integrasse, efetivamente, ao meio social como verdadeiro cidadão. Desse modo, foi enxotado para as margens da sociedade, sem qualquer direito ou proteção estatal, o que levou muitos deles ao retorno às condições precárias de trabalho, posto que se viram obrigados a laborar em troca de um prato de comida (MIRAGLIA, 2011, p. 128).

As formas análogas de escravidão contemporânea são mais vantajosas para os empresários do que na época do Brasil Colônia, porque não se reduzem à população negra, oriunda da África, sendo mais eficiente do ponto de vista financeiro e operacional.

Percebe-se que o trabalho similar ao do antigo escravo se manteve, mas agora com uma nova roupagem, apresentando-se com uma maior frequiência sob a forma de servidão, ou "peonagem" por dívida. Nela, o trabalhador empenha sua própria capacidade de trabalho ou a de pessoas sob sua responsabilidade a fim de que suas dívidas sejam saldadas. E isso acontece sem que o valor do serviço executado seja abatido da conta de forma razoável ou que a duração e a natureza do serviço estejam claramente definidas. A nova escravidão é mais vantajosa para os empresários que a da época do Brasil Colônia, pelo menos do ponto de vista financeiro e operacional, já que as diferenças étnicas não são mais levadas em conta durante a escolha da mão-de-obra e a seleção desta, agora, dá-se apenas quanto à capacidade produtiva (MONTEIRO, 2011).

A forma análoga à escravidão na atualidade alimenta os ideais do capitalismo, retirando a liberdade real dos trabalhadores, que ficam presos por sua própria condição de dependência/hipossuficiência econômica em relação ao seu empregador. Tal situação é agravada nas regiões mais pobres, como em determinadas zonas rurais: 
(...) poderíamos conceituar o trabalho escravo contemporâneo na zona rural, como sendo aquele em que o empregador sujeita o empregado a condições de trabalho degradante, inclusive quanto ao meio ambiente em que irá realizar a sua atividade laboral, submetendo-o, em geral, a constrangimentos físico e moral, que vai desde a deformação do seu consentimento ao celebrar o vínculo empregatício, passando pela proibição imposta ao obreiro de resilir o vínculo quando bem entender, tudo motivado pelo interesse mesquinho de ampliar o lucro às custas da exploração do trabalhador (SENTO-SÉ, 2000, p. 27).

Nesse sentido, muitas usinas de cana-de-açúcar violam a legislação trabalhista, uma vez que trabalhadores não dispõem de banheiros nos locais de trabalho ou a sua existência é precária; grande parte deles não têm água potável para o consumo; o local de trabalho é malcheiroso, contém muita poeira, não tem ventilação devida, nem local adequado para a realização das refeições e descanso; há limitação no uso de Equipamentos de Proteção Individual (EPIs), quando são fornecidos.

O crime de trabalho escravo deve ser caracterizado pela sujeição de uma pessoa a outra, em condição semelhante à de escravo, isto é, à condição deprimente e indigna. O que o artigo 149 do Código Penal procura impedir é o estado de sujeição da vítima ao pleno domínio de alguém, por período de tempo juridicamente relevante, em razão da execução de trabalho em condições desumanas ou indignas (que precisam estar descritas no tipo penal: submissão a trabalhos forçados ou à jornada exaustiva; sujeição a condições degradantes de trabalho; restrição por qualquer meio da locomoção em razão de dívida contraída com o empregador ou o preposto; cerceamento do uso de qualquer meio de transporte por parte do trabalhador, com o fim de retê-lo no trabalho; a manutenção de vigilância ostensiva no local de trabalho; ou o apoderamento de documentos ou objetos pessoais do trabalhador, com a finalidade de retê-lo no lugar de 
trabalho), sendo irrelevante que a vítima tenha ou disponha de relativa liberdade, pois a proteção da lei penal não se limita à liberdade de autolocomoção (BITENCOURT, 2012, p. 599-600).

Em outras palavras, a restrição à liberdade de locomoção do trabalhador é apenas uma das formas de cometimento do delito, mas não é a única, porque o artigo 149 do Código Penal prevê outras condutas que podem ofender o bem jurídico tutelado, ou seja, a liberdade do indivíduo de ir, vir e se autodeterminar (STJ, Resp 1223781/MA, Rel. Ministro Reynaldo Soares da Fonseca, Quinta Turma, julgado em 23/8/2016, DJe $29 / 8 / 2016)$.

Afinal, a violação do direito ao trabalho digno impacta a capacidade da vítima de realizar escolhas conforme a sua livre-determinação (STF, Inq 3412, Relator(a): Min. MARCO AURÉLIO, Relator(a) p/ Acórdão: Min. ROSA WEBER, Tribunal Pleno, julgado em 29/3/2012, ACÓRDÃO ELETRÔNICO DJe-222 DIVULG 09-11-2012 PUBLIC 12-11-2012 RTJ VOL00224-01 PP-00284).

Por outro lado, embora o consentimento do ofendido seja irrelevante para a configuração do crime, não bastam meras irregularidades nas relações trabalhistas para a tipificação do delito. A violação aos direitos do trabalho deve ser intensa e persistente, a ponto de atingir níveis gritantes e submetidos os trabalhadores a trabalhos forçados, jornadas exaustivas ou a condições degradantes de trabalho, posto que o crime do artigo 149 do Código Penal se refere à condição análoga à de escravo, exigindo a configuração da privação de sua liberdade e de sua dignidade (STF, Inq 3412, Relator(a): Min. MARCO AURÉLIO, Relator(a) p/ Acórdão: Min. ROSA WEBER, Tribunal Pleno, julgado em 29/3/2012, ACÓRDÃO ELETRÔNICO DJe-222 DIVULG 09-11-2012 PUBLIC 12-11-2012 RTJ VOL-00224-01 PP-00284). 
Pela Organização Internacional do Trabalho (OIT), a escravidão no Brasil contemporâneo tem traços mais sutis do que no período colonial e, por isso, apresenta características perversas. A mais visível é a falta de liberdade de locomoção, manifestando-se por meio da servidão por dívida, da retenção de documentos, da dificuldade de acesso ao local de trabalho e, ainda, pela presença de guardas armados. Esses fatores são frequentemente acompanhados de condições subumanas de vida e de trabalho, com absoluto desrespeito à dignidade da pessoa humana.

As Convenções 29 e 105 da OIT, as quais se referem ao trabalho forçado e à abolição do trabalho forçado, dispõem que o trabalho forçado não pode ser simplesmente atrelado aos baixos salários ou às más condições de trabalho. Tampouco inclui situações de pura necessidade econômica, como quando um trabalhador sente dificuldade em abandonar um emprego pela ausência real ou suspeitada de alternativas. Mais que isso, o trabalho forçado representa uma grave violação dos direitos humanos e uma restrição à liberdade humana.

O Supremo Tribunal Federal firmou jurisprudência no sentido de ser desnecessário haver violência física para a configuração do delito de redução à condição análoga à de escravo, bastando apenas a coisificação do trabalhador, com a reiterada ofensa a direitos fundamentais, capazes de violar a sua dignidade como ser humano (Inq 3564, Relator(a): Min. Ricardo Lewandowski, Segunda Turma, julgado em 19/8/2014, Acórdão eletrônico DJe-203 divulg. 16-10-2014 public. 17-10-2014; Inq 3.412, Redatora p/ Acórdão: Min. Rosa Weber, Tribunal Pleno, DJe 12/11/2012).

Apesar disso, a Portaria do Ministério do Trabalho $\mathrm{n}^{\mathrm{0}}$ 1.129/2017, publicada no Diário Oficial da União do dia 16/10/2017, ao dispor sobre os conceitos de trabalho forçado, jornada exaustiva e condições análogas à de escravo para fins de concessão de seguro-desemprego ao trabalhador que vier a ser resgatado em fiscalização do Ministério do Trabalho, restringiu, no artigo $1^{\circ}$, inc. IV, letra “a”, o conceito de trabalho em condições 
análogas à de escravo à "submissão do trabalhador a trabalho exigido sob ameaça de punição, com uso de coação, realizado de maneira involuntária”. Tal ato normativo ensejou a imediata reação da Rede Sustentabilidade, que ajuizou, em 20 de outubro de 2017, no Supremo Tribunal Federal (STF), a Arguição de Descumprimento de Preceito Fundamental (ADPF 489), pedindo a concessão de medida liminar para suspender os efeitos da Portaria. Do mesmo modo, a Confederação Nacional das Profissões Liberais (CNPL) ajuizou ação ADPF (491), argumentando que a Portaria 1.129/2017, do Ministério do Trabalho, fere precedente do próprio STF no sentido de que, para configurar trabalho escravo, não é necessário que se prove a coação física da liberdade de ir e vir ou mesmo o cerceamento da liberdade de locomoção, bastando a submissão da vítima a trabalhos forçados ou à jornada exaustiva ou condições degradantes de trabalho.

A ministra Rosa Weber deferiu a liminar na Arguição de Descumprimento de Preceito Fundamental $n^{0} 489$, suspendendo a Portaria $n^{\circ}$ 1.129/2017 do Ministério do Trabalho que altera as regras de fiscalização no combate ao trabalho escravo e cria nova definição aos conceitos de trabalho forçado, jornada exaustiva e condições análogas à de escravo, para, entre outros fins, a concessão de seguro-desemprego.

A ministra Rosa Weber afirmou que não é qualquer violação dos direitos trabalhistas que configura trabalho escravo, mas se ela atinge níveis gritantes e se submetidos os trabalhadores a trabalhos forçados, jornadas exaustivas ou a condições degradantes, com a privação de sua liberdade ou dignidade, caracteriza-se o trabalho na condição análoga ao de escravos, conforme a definição do artigo 149 do Código Penal, ainda que ausente a coação direta contra a liberdade de ir e vir. Desse modo, a Portaria $\mathrm{n}^{\mathrm{0}}$ 1.129/2017 do Ministério do Trabalho esvazia os conceitos de jornada exaustiva de trabalho e de trabalho forçado, introduz sem base legal o "isolamento geográfico" como elemento necessário à caracterização de cerceamento do uso dos meios de transporte pelo trabalhador, 
além de colocar a presença armada como requisito para a configuração da retenção coercitiva do trabalhador no local de trabalho em razão de dívida contraída. Por tudo isso, na avaliação da ministra relatora, a referida Portaria muda o conceito de trabalho análogo ao de escravo, atenuando as políticas de repressão, de prevenção e de reparação às vítimas, o que contraria 20 anos de trajetória jurídica e administrativa realizada pelo Brasil no combate à escravidão contemporânea, que, ainda assim, não impediram que o país fosse condenado pela Corte Interamericana de Direitos Humanos no caso Fazenda Brasil Verde.

Com efeito, seguindo a orientação do STF, sob pena de retrocesso social, a caracterização do trabalho escravo não exige coação física ou cerceamento da liberdade de locomoção, podendo ser demonstrado pela combinação de vários elementos, tais como: a servidão por dívida, a retenção de documentos, o isolamento físico e a vigilância ostensiva (TREVISAM, 2015, p. 83).

Além disso, é relevante discorrer sobre esse tema com a finalidade de sensibilizar a sociedade quanto ao combate e erradicação do trabalho escravo contemporâneo, acentuando a necessidade de afirmação dos direitos humanos violados pela prática da escravidão. Esse assunto também é importante para esclarecer os cidadãos brasileiros sobre os direitos trabalhistas, bem como reforçar a importância de construir uma rede de informações e proteção para enfrentar esse tipo de exploração.

\section{A CONSTRUÇÃO DOS DIREITOS HUMANOS COM FOCO NA INCLUSÃO SOCIAL}

A partir de meados do século 20, os direitos da pessoa humana ganharam extrema relevância, consagrando-se internacionalmente como resposta aos horrores praticados nos campos de concentração da Alemanha nazista. 
Para Hitler, apenas os descendentes da raça superior ariana deveriam fazer $j u s$ aos direitos humanos, enquanto as demais pessoas poderiam ser descartadas. Assim, a dignidade não constituía um atributo do ser humano como um todo, mas somente dos membros da raça ariana.

Nos campos de extermínio nazistas, os judeus eram assassinados pelo ódio alimentado pelo governo alemão, independentemente de vícios ou virtudes pessoais.

Como ressalta Hannah Arendt, “os próprios assassinos, apenas seguindo ordens e orgulhosos de sua desapaixonada eficiência, assemelhavam-se sinistramente aos instrumentos 'inocentes' de um ciclo inumano e impessoal de eventos, exatamente como os considerava a doutrina do eterno antissemitismo" (1991, p. 33).

Diante das atrocidades cometidas pelo Holocausto, foram criados mecanismos internacionais (universais) para a garantia de direitos do indivíduo perante os Estados.

O Processo de universalização dos direitos humanos permitiu a formação de um sistema internacional de proteção desses direitos. Tal sistema é integrado por tratados internacionais de proteção que refletem, sobretudo, a consciência ética contemporânea compartilhada pelos Estados, na medida em que invocam o consenso internacional acerca de temas centrais aos direitos humanos, na busca da salvaguarda de parâmetros protetivos mínimos - do "mínimo ético irredutível" (PIOVESAN, 2015, p. 49).

A concepção contemporânea de direitos humanos foi introduzida pela Declaração Universal dos Direitos Humanos de 1948 e reiterada pela Declaração de Direitos Humanos de Viena de 1993, mas ganhou força ao longo do tempo pela reiterada observância pelos Estados que compõem a Organização das Nações Unidas (ONU). 
No âmbito jurídico, a Declaração Universal dos Direitos Humanos nasceu com a significativa força de uma importante carta de intenções, dos membros da ONU, mas não como a obrigatoriedade de um tratado. Ao longo dos anos de aplicação, sua natureza jurídica foi se transformando de tal maneira que sua respeitabilidade perante os Estados já se considera fluente do Direito Costumeiro, em razão das reiteradas menções ao seu conteúdo em documentos importantes, bem como nas jurisprudências dos Estados e de Tribunais Internacionais (ÁVILA, 2014, p. 245-246).

Dessa forma, a concepção contemporânea dos direitos humanos decorre da sua internacionalização, movimento recente na História, tendo em vista que surgiu a partir do Pós-Guerra, justamente para que os horrores cometidos durante o nazismo não fossem repetidos (PIOVESAN, 2015, p. 49).

Trata-se de um novo paradigma centrado nas relações Estado/povo, fundado na emergência de um Direito Internacional dos Direitos Humanos e na tendencial elevação da dignidade da pessoa humana a pressuposto de todos os constitucionalismos (PIOVESAN, 2015, p. 49).

Considerando que o direito ao trabalho é um direito humano fundamental, a manutenção da escravidão fere os direitos humanos consagrados, pois, na atualidade, o ato de escravizar é delineado por sutis atrocidades, tais como a geração de riqueza à custa da ofensa à dignidade humana e o desrespeito à vida e à moral do ser humano, todas razões suficientes para fundamentar a luta pelo extermínio do trabalho escravo contemporâneo.

\section{O CLAMOR PELA EFETIVIDADE DOS DIREITOS HUMANOS NO TOCANTE À MARGINALIZAÇÃO SOCIAL}

A efetividade dos direitos humanos constitui a materialização das normas jurídicas no mundo fático, isto é, decorre da aproximação entre o dever ser normativo e o ser da realidade social (BARROSO, 1996, p. 83). 
Há grande dificuldade de se constatar efetivamente o alcance de alguns direitos humanos, com especial destaque para os direitos sociais, caracterizados como direitos prestacionais. Isso porque esses direitos, além de concretização normativa, dependem de circunstâncias de natureza socioeconômica (SARLET, 2012, p. 297-298).

Por isso, não basta reconhecer, descrever e relacionar os direitos humanos fundamentais, sendo indispensável a existência de políticas públicas sociais, além de esforços conjuntos do Estado e da sociedade para que esses direitos se tornem realmente eficazes.

É certo que muitas ações humanas estão condicionadas pelo viés econômico. Há, porém, um afastamento da humanidade e uma aproximação da desumanidade, quando o direito sucumbe ao poder econômico, que concentra cada vez mais riquezas em um número menor de pessoas, com a elevação das desigualdades e das injustiças, a promoção da miséria e a marginalização social.

A concentração do poder econômico também contribui para a perpetuação das violências e para fortalecer os sentimentos de intolerância, preconceito, individualismo e desrespeito à dignidade da pessoa humana. Tudo isso faz com que milhões de pessoas vivenciem situações de desumanidade em pleno século 21.

Esse cenário aponta para a crise atual dos direitos humanos. Afinal, apesar de esses direitos terem sido desenvolvidos após a Segunda Grande Guerra, ainda não foram minimamente efetivados, não proporcionando à grande parte da população mundial o direito ao trabalho digno.

A falta de efetividade dos direitos humanos precisa ser amplamente discutida e estudada a fim de que o abismo entre a teoria e a prática seja cada vez mais minimizado, sendo imperiosa a participação do cidadão, da sociedade civil organizada e dos Estados na concretização desses direitos. 


\section{O TRABALHO EM CONDIÇÕES ANÁLOGAS ÀS DE ESCRAVO COMO GRAVE VIOLAÇÃO DOS DIREITOS HUMANOS}

O trabalho em condições análogas às de escravo exprime uma mazela social enrustida pela modernidade, que explora os trabalhadores mais pobres e vulneráveis.

Enrique Dussel afirma que a acumulação de riqueza acarreta, por outro lado, miséria, pobreza, escravidão e tormento (2000, p. 109). Logo, as vítimas são seres oprimidos, marginalizados e sem qualificação profissional, que sofrem com a exclusão social, pois são simplesmente invisiveis aos olhos da sociedade, que consome os produtos frutos dos trabalhos dos escravos contemporâneos, mas não os enxergam como seres humanos.

Essa forma degradante de trabalho se mantém em razão da persistência de empregadores com mentalidade e comportamento escravocratas, que reproduzem a opressão e a humilhação aos trabalhadores, violando seus direitos humanos para auferirem lucros ainda maiores.

O trabalho em condições análogas a de escravo, por ser forçado ou obrigatório, além de realizado em condições humilhantes, desrespeita a dignidade da pessoa humana, infringindo o disposto no artigo $1^{\circ}$, inciso III, da Constituição Federal.

Dignidade é a qualidade intrínseca e distintiva de cada ser humano que o faz merecedor do mesmo respeito e consideração por parte do Estado e da comunidade, implicando, neste sentido, um complexo de direitos e deveres fundamentais que assegurem a pessoa tanto contra todo e qualquer ato de cunho degradante e desumano, como venham a lhe garantir as condições existenciais mínimas para uma vida saudável, além de propiciar e promover sua participação ativa e co-responsável nos destinos da própria existência e da vida em comunhão com os demais seres humanos (SARLET, 2012, p. 73). 
Dessa forma, para que os direitos humanos venham a integrar as relações de trabalho, garantindo a inexistência da escravidão, é necessário a adoção de políticas públicas e de conscientização social voltadas para: elucidar sobre a importância da repressão do trabalho em condições análogas às de escravo; esclarecer sobre a necessidade da promoção de ações preventivas e inclusivas das vítimas e das pessoas em situação de vulnerabilidade; demonstrar a legislação nacional e internacional a respeito do trabalho escravo contemporâneo; disseminar a conscientização, trabalhando também fora da comunidade jurídica por meio de atividades interdisciplinares, levando essas informações a respeito do trabalho escravo contemporâneo à comunidade, com o objetivo de discutir sobre o valor do trabalho e o seu papel na sociedade de maneira geral; informar a sociedade sobre os direitos trabalhistas; despertar na comunidade escolar os princípios de cidadania diante dos méritos trabalhistas e reforçar a importância de construir uma rede de informações e de proteção para enfrentar problemas comuns em relação à exploração do trabalho.

Em pleno século 21, a erradicação da escravidão depende da humanização do próprio ser humano enquanto empregador, acompanhada do controle social e da rigorosa responsabilização criminal de condutas que reduzam a condição análoga à de escravo, para que seja possível a geração de empregos dignos, condizentes com a legislação trabalhista e com a qualidade de vida almejada pelos trabalhadores vítimas da escravidão contemporânea.

Nesse sentido, vale destacar a criação de um grupo de trabalho, no âmbito do Ministério Público Federal, com a finalidade de definir a política criminal de combate à escravidão. Além de uma campanha de sensibilização social para o tema, houve a preocupação de estruturação dos dados, por meio do business inteligence do trabalho escravo, com o objetivo de reunir informações de todos os órgãos envolvidos na erra- 
dicação do trabalho escravo. A iniciativa venceu o Prêmio do Conselho Nacional do Ministério Público, na categoria Diminuição da Criminalidade e da Corrupção, em 2014.

Ocorre que, apesar da existência de ações que promovem a erradicação do trabalho escravo contemporâneo, ainda há muito a ser feito para que se extermine integralmente essa prática. Todo o esforço, no entanto, é válido, seja para o combate dessa mazela social, seja para a inclusão social por meio de políticas públicas eficientes daqueles que são vítimas da sua própria miséria.

\section{CONSIDERAÇÕES FINAIS}

O trabalho escravo nos dias de hoje reflete uma realidade em que a pobreza e a exploração humanas ainda marcam a vida de milhares de cidadãos brasileiros. Há a permanência de empregadores com comportamentos escravocratas, o que revela uma face desumana do capitalismo, que, corriqueiramente, visa simplesmente ao lucro em detrimento da justa distribuição de renda e do respeito aos direitos fundamentais dos trabalhadores.

Em pleno século 21, a persistência do trabalho escravo evidencia grave violação de direitos intrínsecos aos seres humanos. Afinal, o trabalho deve proporcionar o seu desenvolvimento integral, não devendo ser motivo de sofrimento.

Considerando que a escravidão contemporânea exclui o trabalhador, há que se pensar em soluções que promovam justiça social, a fim de proporcionar a redistribuição de riqueza pelo trabalho digno.

Assim, é importante ressaltar o valor social do trabalho, fundado no exercício formal e qualificado, como meio de proteção da dignidade do trabalhador. 
Para a erradicação do trabalho escravo, faz-se necessária a conscientização da sociedade, a construção de políticas públicas eficientes, o fortalecimento de redes de proteção e a rigorosa responsabilização daqueles que promovem o trabalho escravo tanto no meio urbano quanto rural.

\section{REFERÊNCIAS}

ARENDT, Hannah. A condição humana. Tradução Roberto Raposo; posfácio Celso Lafer. 5. ed. São Paulo: Forense Universitária, 1991.

ÁVILA, Flávia de. Direito e direitos humanos: abordagem histórico-filosófica e conceitual. Curitiba: Appris, 2014.

BARROSO, Luís Roberto. O direito constitucional e a efetividade de suas normas: limites e possibilidades da Constituição brasileira. Rio de Janeiro: Renovar, 1996.

BITENCOURT, Cezar Roberto. Código Penal comentado. 7. ed. São Paulo: Saraiva, 2012.

BLACKBURN, Robin. A construção do escravismo no Novo Mundo: do barroco ao moderno, 1492-1800. Rio de Janeiro: Record, 2003.

BRASIL. Organização Internacional do Trabalho. Perfil dos principais atores envolvidos no trabalho escravo rural no Brasil. Brasília: OIT, 2011. p. 57.

. Superior Tribunal de Justiça, Resp 1223781/MA, Rel. Ministro Reynaldo Soares da Fonseca, Quinta Turma, julgado em 23/8/2016, DJe 29/8/2016.

. Supremo Tribunal Federal, Inq 3412, Relator(a): Min. MARCO AURÉLIO, Relator(a) p/ Acórdão: Min. ROSA WEBER, Tribunal Pleno, julgado em 29/3/2012, ACÓRDÃO ELETRÔNICO DJe-222 DIVULG 09-11-2012 PUBLIC 12-11-2012 RTJ VOL-00224-01 PP-00284.

Supremo Tribunal Federal. Inq 3564, Relator(a): Min. Ricardo Lewandowski, Segunda Turma, julgado em 19/8/2014, Acórdão eletrônico DJe-203 divulg. 16-10-2014 public. 17-10-2014; Inq 3.412, Redatora p/ Acórdão: Min. Rosa Weber, Tribunal Pleno, DJe 12/11/2012. 
CASSAR, Vólia Bomfim. Direito do trabalho. Rio de Janeiro: Impetus, 2008. COMPARATO, Fábio Konder. A afirmação histórica dos direitos humanos. 2. ed. São Paulo: Saraiva, 2001.

COOPER, Frederick; HOLT, Thomas C.; SCOTT, Rebeca J. Além da escravidão: investigações sobre raça, trabalho e cidadania em sociedades pós-emancipação. Rio de Janeiro: Civilização Brasileira, 2005. p. 238.

COSTA E SILVA, Alberto da. História do Brasil Nação - 1808-2016. Rio de Janeiro: Objetiva, 2012.

DELGADO, Maurício Godinho. Princípios de direito individual e coletivo do trabalho. 4. ed. São Paulo: LTR, 2013.

DUSSEL, Enrique. Ética da libertação na idade da globalização e da exclusão. Petrópolis: Ed. Vozes, 2000.

GIACÓIA, Gilberto. Justiça e dignidade. Argumenta, Jacarezinho, n. 2, p. 11-31, 2002.

MACHADO, Sidnei. Trabalho escravo e trabalho livre no Brasil: alguns paradoxos históricos do direito do trabalho, 2012. Disponível em: <http://ojs. c3sl.ufpr.br/ojs2/index.php/direito/article/view/1766/1463>. Acesso em: 8 out. 2015.

MAZZILLI, Hugo Nigro. A defesa dos interesses difusos em juizo: meio ambiente do trabalho, consumidor, patrimônio cultural e outros interesses. 26. ed. São Paulo: Saraiva, 2013.

MIRAGLIA, Lívia Mendes Moreira. Trabalho escravo contemporâneo: conceituação à luz do princípio da dignidade da pessoa humana. São Paulo: LTR, 2011. MONTEIRO, Mariah. A escravidão contemporânea do setor sucro-alcooleiro. 2011. Disponível em: <http://www.criticadodireito.com.br/todas-as-edicoes/ numero-1-volume-17/a-escravidao-contemporanea-do-setor-sucro-alcooleiro> . Acesso em: 5 out. 2015.

ORGANIZAÇÃO INTERNACIONAL DO TRABALHO (OIT). 2011. Disponível em: <http://www.oitbrasil.org.br>. Acesso em: 18 jun. 2017. 
PAULA, Paulo Mazzante. Trabalho informal e exclusão social. Bauru: Canal 6 Editora, 2012.

PIOVESAN, Flávia. Trabalho escravo e degradante como forma de violação dos direitos humanos. In: NOCCHI, Andrea Saint Pastous; VELLOSO, Gabriel Napoleão; FAVA, Marcos Neves (Coord.). Trabalho escravo contemporâneo: o desafio de superar a negação. 2. ed. São Paulo: LTR, 2011.

Direitos humanos e justiça internacional. 6. ed. São Paulo: Saraiva, 2015.

SAKAMOTO, Leonardo. A economia do trabalho escravo no Brasil contemporâneo. In: CERQUEIRA, G. C. et al. (Org.). Trabalho escravo contemporâneo no Brasil: contribuições críticas para sua análise e denúncia. Rio de Janeiro: Ed. UFRJ, 2008.

SARLET, Ingo Wolfgang. Dignidade da pessoa humana e direitos fundamentais na Constituição Federal de 1988. 9. ed. Porto Alegre: Livraria do Advogado Editora, 2012.

SENTO-SÉ. Jairo Lins de Albuquerque. Trabalho escravo no Brasil. São Paulo: LTR, 2000.

SILVA, Marcelo Ribeiro. Trabalho análogo ao de escravo rural no Brasil do século XXI: novos contornos de um antigo problema. 2010. Dissertação (Mestrado) - Universidade Federal de Goiás, Goiânia, 2010.

TREVISAM, Elisaide. Trabalho escravo no Brasil contemporâneo. Curitiba: Juruá, 2015.

VIANA, Márcio Túlio. Trabalho escravo e "lista suja”: um modo original de se remover uma mancha. Revista LTR, vol. 71, n. 8, p. 925-938, ago. 2007. 